\title{
Identifikasi Zona Alterasi Hidrotermal Songgoriti Batu Menggunakan Metode Time Domain Induced Polarization (TDIP)
}

\author{
Tricahyo Agung Budi Harjo, Ayi Syaeful Bahri , dan Widya Utama \\ Departemen Teknik Geofisika, Fakultas Teknik Sipil dan Perencanaan, Institut Teknologi Sepuluh Nopember (ITS) \\ e-mail: syaeful_b@geofisika.ac.id
}

\begin{abstract}
Abstrak-Alterasi hidrotermal terjadi sebagai akibat dari interaksi aliran hidrotermal dan batuan disekitarnya. Aliran hidrotermal ini melewati batuan disekitarnya dan mengakibatkan terjadinya ubahan, baik kandungan kimia batuan ataupun tekstur batuan tersebut. Zona alterasi hidrotermal dapat diketahui melalui metode induced polarization dalam domain waktu. Area penelitian adalah manifestasi hidrotermal yang terletak di Songgoriti, Batu. Oleh karena itu pada penelitian studi ini dilakukan akuisisi data menggunakan metode induced polarization domain waktu dengan data pendukung vertical electrical sounding. Hasil yang didapat berupa adanya indikasi zona alterasi hidrotermal pada lintasan SONGGORITI 1dan SONGGORITI-2. Zona alterasi hidrotermal diindikasikan bertipe argilic dengan mineral penciri berupa clay mineral seperti montmorilonit dan halloycyte. Hal tersebut didukung dari nilai pengukuran $\mathrm{PH}$ pada manifestasi hidrotermal yang mendekati netral yaitu antara 6.31 - 6.51. Indikasi adanya zona alterasi hidrotermal ditandai dengan adanya zona konduktif yang berada di kedalaman dangkal mulai dari 9 meter sampai dengan 20 meter dengan nilai chargeability $>22$ msec.
\end{abstract}

ata Kunci-Alterasi hidrotermal, Clay mineral, Chargeability, Induced Polarization.

\section{PENDAHULUAN}

$S_{b}^{o}$ ONGGORITI merupakan salah satu daerah prospek panas bumi dengan kapasitas 25 MWe [1]. (Badan Geologi, 2009). Daerah prospek panas bumi ditandai oleh adanya kolam air panas (hotspring) dan alterasi hidrotermal [2]. Interaksi fluida hidrotermal dengan batuan yang dilaluinya mengakibatkan perubahan secara mineralogi, kimiawi dan tekstur batuan [3]. Diperlukan identifikasi bawah permukaan yang mampu melokalisir zona alterasi yang diakibatkan oleh aliran hidrotermal. Daerah alterasi hidrotermal memiliki resistivitas yang rendah dan chargeability yang tinggi (zona konduktif) [4]. Metode yang dapat digunakan dalam menentukan nilai resistivity dan chargeability adalah time domain induced polarization (TDIP).

Metode induced polarization dengan konfigurasi WennerSchlumberger memiliki resolusi data yang baik secara vertikal dan horizontal [5]. Metode ini digunakan untuk mengetahui struktur bawah permukaan melalui distribusi nilai chargeability. Oleh karena itu dalam penelitian ini ditentukan persebaran chargeability tinggi dan nilai resistivitas rendah yang diindikasikan sebagai zona alterasi (ubahan) hidrotermal di daerah Songgoriti,Batu dengan metode time domain induced polarization (TDIP) konfigurasi Wenner-Schlumberger.
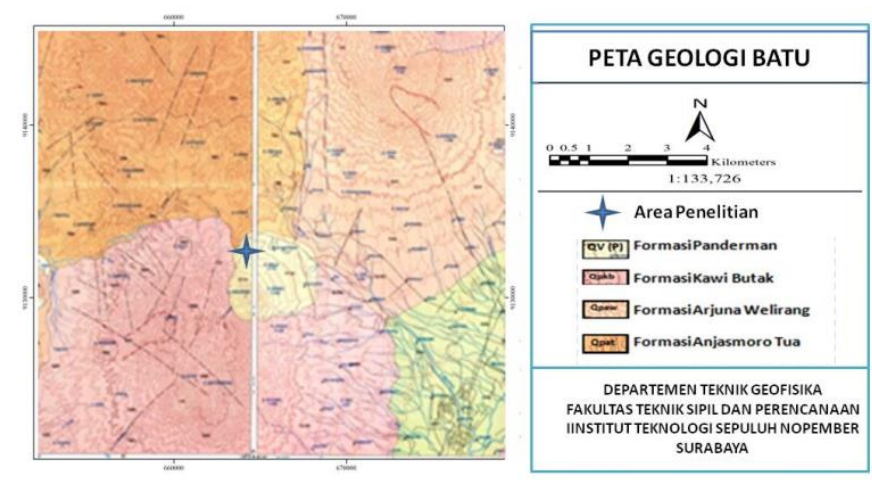

Gambar. 1 Peta Geologi Batu dan Sekitarnya.

Daerah penelitian termasuk dalam pegunungan dan perbukitan vulkanik berumur kuarter dengan batuan yang mendominasi daerah ini adalah tuff pasiran, tuf breksi. Berdasarkan peta geologi lembar Kediri dan lembar Batu, daerah Songgoriti berada di kaki Gunung Butak - Kawi, Gunung Arjuna-Welirang dan Gunung Anjasmoro Tua. [6] Pada akhir plistosen terjadi aktivitas vulkanik Gunung Kawi Butak (Qpvp) yang berada di selatan Songgoriti dan Gunung Arjuna Welirang (Qvaw) yang berada di sisi timur dan utara Songgoriti. Hasil letusan Gunung Kawi - Butak (Qpvp) berupa lava andesit, tuf, dan breksi vulkanik. Hasil endapan aktifitas Gunung Panderman (Qvp) di bagian selatan berupa breksi gunungapi, tuf breksi, lava dan tuf. Struktur geologi yang mempengaruhi daerah ini berupa sesar-sesar mendatar di bagian selatan dan sebagian berupa sesar turun akibat dari letusan gunung api. Sesar-sesar inilah yang membawa manisfestasi dari dalam keluar permukaan [7].

Penggunaan metode time domain induced polarization pada penelitian ini berdasarkan konsep mengalirkan arus listrik kedalam bumi dan mengamati beda potensial yang terjadi setelah arus listrik dihentikan. Pada saat arus diinjeksikan, ionion dalam pori-pori batuan akan terdistribusi dari posisi stabil menjadi tidak stabil. Ketika arus diputus, beda potensial akan menjadi nol, akan tetapi pada medium-medium tertentu beda potensial tidak langung menjadi nol dikarenakan medium bersifat seperti kapasitor yang menyimpan energi listrik. 


$$
M a=\frac{1}{V} \int_{t 1}^{t 2} V(t) d t
$$

Apparent chargeability menunjukkan lama tidaknya efek polarisasi sesaat setelah arus dimatikan. Apabila waktu delay lama maka nilai Ma besar sehingga dapat diamsusikan adanya mineral konduktif.

Penelitian ini menggunakan konfigurasi WennerSchlumberger karena memiliki keunggulan yaitu data yang dihasilkan memiliki resolusi yang baik. Faktor geometris (k) konfigurasi Wenner-Schlumberger diperoleh berdasarkan formulasi sebagai berikut:

$$
\mathrm{k}=n(n+1) \pi a
$$

Spasi antara dua elektroda potensial sama yaitu a. Konfigurasi ini mempunyai faktor lain yaitu $n$ yang merupakan rasio jarak antara elektroda $\mathrm{C} 1$ dan $\mathrm{P} 1$ ke $\mathrm{C} 2$ dan $\mathrm{P} 2$ dengan jarak pisah a.

\section{METODOLOGI PENELITIAN}

Akuisisi data dilakukan pada titik yang menunjukkan anomali lateral isopotensial. Daerah alterasi hidrotermal memiliki nilai beda potensial yang tinggi. Terdapat 2 lintasan pengukuran dengan bentangan $\mathrm{AB} 100$ meter dengan spasi yang digunakan adalah 2,5 meter.

Elektrode ditancapkan pada lintasan sesuai konfigurasi yang digunakan yaitu Wenner.-Schlumberger. Pengukuran induced polarization dilakukan dengan cara menginjeksikan arus ke dalam tanah melalui dua elektroda arus (C1 dan $\mathrm{C} 2)$, dan mengukur hasil beda potensial yang ditimbulkannya pada dua elektroda potensial (P1 dan P2) menghitung tegangan sekunder saat arus diputus dan waktu yang diperlukan untuk meluruh. Hasil akuisisi data lapangan berupa nilai Vp (tegangan primer), Vs (tegangan sekunder), I (arus) dan waktu peluruhan (t). Perhitungan nilai apparent chargeability menggunakan persamaan (1). Data - data tersebut selanjutnya di inversi dengan menggunakan metode least square pada Res2dINV yang telah memiliki lisensi. Inversi ini bertujuan untuk mendapatkan model bawah permukaan bumi melalui data pengukuran (observasi). Distribusi nilai chargeabilitas dalam 2Dimensi diasumsikan sebagai litologi bawah permukaan.

\section{HASIL DAN DISKUSI}

\section{A. Zona Alterasi Hidrotermal SONGGORITI}

Hasil penampang induced polarization lintasan SONGGORITI-1 menunjukkan rentang nilai chargeabilitas antara -5 msec sampai dengan $26.5 \mathrm{msec}$. Nilai chargeabilitas negatif (-) dengan warna biru menunjukkan litologi berupa soft clay seperti pada penelitian [8]. Adanya soft clay memberikan informasi hadirnya halloysit [9]. Litologi ini tersebar dipermukaan lintasan SONGGORITI-1. Litologi ini tersebar dipermukaan lintasan SONGGORITI-1.

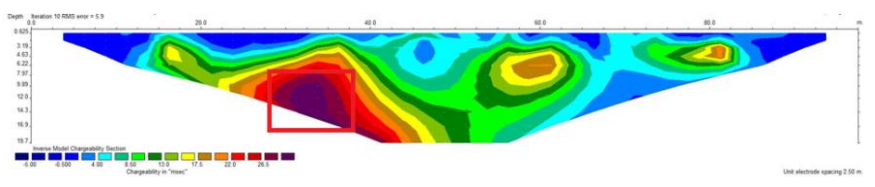

Gambar 2. Penampang 2D Chargeabilitas Lintasan SONGGORITI-1
Pada penampang chargeabilitas lintasan SONGGORITI-1 zona alterasi hidrotermal memiliki nilai chargeabilitas yang tinggi yaitu > 22 msec (tanda kotak merah) pada gambar 2 . Dasar penentuan ini adalah [10]. Zona alterasi hidrotermal pada penampang resistivitas menunjukkan nilai yang rendah, yaitu 3,1 ohm meter sampai dengan $27 \mathrm{ohm}$ meter [11]. Chargeabilitas untuk daerah alterasi hidrotermal memiliki nilai yang tinggi akibat adanya pengaruh mineral konduktif. Sehingga dapat dikatakan adanya keterkaitan antara nilai chargeabilitas dengan nilai resistivitas pada penelitian ini dalam menentukan zona alterasi hidrotermal.

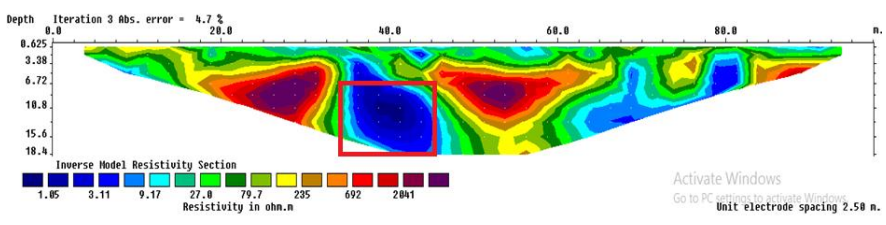

Gambar 3. Penampang 2D Resistivitas Lintasan SONGGORITI-1

Zona alterasi hidrotermal ini memiliki tipe alterasi argilik. Hal tersebut didukung dengan pengambilan sampel fluida hidrotermal disekitar lintasan ini yang memiliki nilai $\mathrm{PH}$ asam lemah dengan nilai PH 6,31-6,51 (asam lemah) .Nilai anomali chargeabilitas yang tinggi di kedalaman dangkal dengan rentang $20 \mathrm{msec}-30 \mathrm{msec}$ sangat berhubungan dengan clay mineral akibat dari alterasi bertipe argilik [12].

\section{B. Vertical Electrical Sounding SONGGORITI}

Terdapat hubungan antara hasil pengolahan VES dengan hasil pengolahan induced polarization lintasan SONGGORITI1. Pada penampang 2D chargeabilitas zona alterasi hidrotermal terdapat di kedalaman 10 meter sampai 18 meter yang berada pada tanda kotak merah pada Gambar 2. dengan nilai chargeabilitas $>22 \mathrm{msec}$. Pada penampang VES di kedalaman 8,5 meter sampai dengan 12 meter terdapat resisitivitas rendah yaitu $20 \mathrm{ohm}$ meter, seperti pada Gambar 3. Oleh karena itu daerah ini diinterpretasikan sebagai daerah alterasi hidrotermal. Alterasi hidrotermal memiliki resisitivitas rendah $<100$ ohm.meter [13].

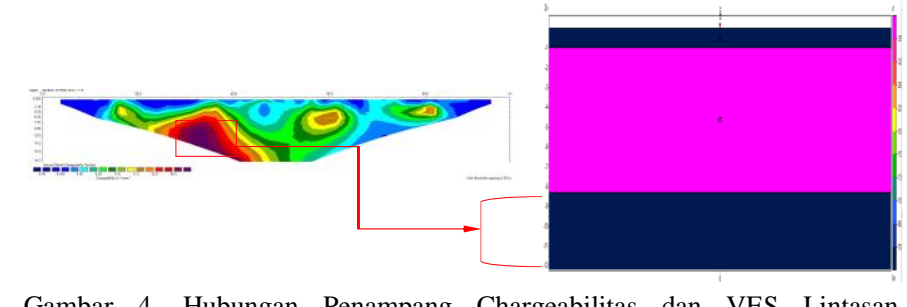

Gambar 4. Hubungan Penampang Chargeabilitas dan VES Lintasan SONGGORITI-1

Dari lintasan SONGGORITI-1 diperoleh distribusi resistivitas secara vertikal yang diinterpretasikan sebagai litologi bawah permukaan.

Tabel 1.

Identifikasi Jenis Tanah dan Batuan Songgoriti

\begin{tabular}{llll}
\hline \hline Lintasan & $\begin{array}{l}\text { Kedalaman } \\
\text { (meter) }\end{array}$ & $\begin{array}{l}\text { Nilai } \\
\text { Resistivitas } \\
\text { (ohm-meter) }\end{array}$ & $\begin{array}{l}\text { Jenis Tanah atau } \\
\text { Batuan }\end{array}$ \\
\hline 1 & $0-0.98$ & 60.14 & Clay
\end{tabular}


JURNAL TEKNIK ITS Vol. 6, No. 2 (2017), 2337-3520 (2301-928X Print)

$\begin{array}{lll}0.98-8.30 & 657.2 & \text { Breksi Tufan } \\ 8.30-12 & 20 & \begin{array}{l}\text { Clay (Alterasi } \\ \text { hidrotermal) } \\ \text { Breksi Tufan }\end{array} \\ >12 & 106.18 & \text {. }\end{array}$

\section{Karakteristik Zona Alterasi Hidrotermal}

Pada kedalaman dangkal sekitar 2,5 meter terdapat indikasi alterasi hidrotermal tipe argilik dengan mineral penciri berupa halloysit. Nilai resistivitas pada daerah tersebut rendah $0,3 \mathrm{ohm}$ meter sampai dengan $27 \mathrm{ohm}$ meter ,oleh karena itu daerah alterasi hidrotermal yang berada pada kedalaman dangkal diinterpretasikan memiliki pola disseminated (menyebar). Hal tersebut didukung dengan penampang VES yang menunjukkan nilai resistivitas $<100 \mathrm{ohm}$. Zona alterasi hidrotermal diakibatkan oleh dinding di sekitar batuan berinteraksi dengan fluida hidrotermal, clay mineral terdapat pada pori-pori batuan. Besar kecilnya nilai chargeabilitas bergantung pada penyebaran difusi ion-ion menuju mineral-mineral logam dan pergerakan ion-ion elektrolit didalam pori batuan. Oleh karena semakin besar nilai chargeabilitas ,maka semakin besar potensi daerah tersebut mengandung mineral konduktif.

\section{KESIMPULAN}

\section{A. Simpulan}

Berdasarkan hasil dan pembahasan pada bab sebelumnya, kesimpulan dari penelitian ini adalah sebagai berikut:

1) Zona alterasi ditandai dengan nilai chargeability tinggi yaitu $>22 \mathrm{msec}$.

2) Karakteristik alterasi hidrotermal didaerah penelitian memiliki tipe argilik dengan mineral penciri halloysit. Alterasi argilik memiliki PH asam lemah 6,31-6,41.

\section{B. Saran}

Saran dari hasil penelitian ini adalah sebagai berikut:

Penelitian ini dapat dikembangkan untuk melakukan estimasi temperatur reservoir panas bumi dengan menggunakan analisis geotermometer.

\section{DAFTAR PUSTAKA}

[1] B. Geologi, Potensi Energi Panas Bumi. Bandung: PSDG Bandung, 2008.

[2] R. Dipippo, "Ideal Thermal Efficiency for Geothermal Binary Plants," ScienceDirect, 2007.

[3] F. Maskuri, "Eksplorasi Mineral EmasJIK Tekmin," UPN, vol. 23, no. $2,2010$.

[4] D. Tezel, Okan, "The Time Domain IP method in Geothermal Exploration: Balikesir (Gure) in Turkey Proceedings World Geothermal Congress," 2010.

[5] W. dan Ansori, "Studi Induced Polarization (IP) untuk Eksplorasi Mineral Mangan di Daerah Srati, Kecamatan Ayah Kabupaten Kebumen, JawaTengah," 2009.

[6] Santoso, Peta Geologi Batu-Kediri. Pusat Sumber Daya Geologi, 1992.

[7] Nuha, "Pemodelan Struktur Bawah Permukaan Daerah Sumber Air Panas Songgoriti Kota Batu Berdasarkan Data Geomagnet," J. Neutrino, 2012.

[8] T. Dahlin, "Negative Apparent Chargeability in Time- Domain Induced Polarization," J. Appl. Geophys., 2015.

[9] S. Boordepong, "Characterization of Halloysite From Thung Yai District Nakhon Si Thammarat Province in Southern Thailand," $J$. Soungklanakrin, vol. 33, no. 5, pp. 599-607, 2011.

[10] S. Rahmah, "Pencitraan Dua Dimensi Data Resistivity dan Induced Polarization Untuk Mendelineasi Deposit Emas Sistem Epitermal X," Univ. Indones., 2011.

[11] F. Alfiansyah, "Analisis Persebaran Zona Alterasi Hidrotermal Songgoriti Menggunakan Metode Tahanan Jenis Konfigurasi Wenner Schlumberger," ITS, 2017.

[12] I. Sulistyarini, "Aplikasi Metode Geolistrik Dalam Survey Potensi Hidrotermal (Studi Kasus: Sekitar Manifestasi Air Panas Songgoriti," 2011.

[13] D. Ariesandra, "Karakterisasi Cebakan Mineral Sulfida Berdasarkan Hasil Metode Geolistrik Resistivitas dan Induced Polarization Daerah Jampang Kabupaten Sukabumi,” J. Fibusi, vol. 3, no. 1, 2015. 